\title{
Editorial
}

\section{Dynamics of Evolving Fluid Interfaces - DEFI Gathering Physico-Chemical and Flow Properties}

\author{
Frédéric Augier ${ }^{1, *}$, Isabelle Henaut ${ }^{2}$ and Guillaume Vinay ${ }^{2}$ \\ 1 IFP Energies nouvelles, Rond-point de l'échangeur de Solaize, BP 3, 69360 Solaize - France \\ 2 IFP Energies nouvelles, 1-4 avenue de Bois Préau, 92852 Rueil-Malmaison Cedex - France \\ e-mail: frederic.augier@ifpenergiesnouvelles.fr \\ *Corresponding author
}

Designing industrial processes involving several fluid phases (gas or liquid) can involve several complex physic-chemical issues due to the interfacial or bulk properties of the fluids: non-Newtonian fluids, presence of surfactants, contaminants, etc. These properties govern phenomena such as breakage/coalescence of bubbles or droplets, emulsion generation, foaming and material transfer through often deformable interfaces. Understanding and modeling these simultaneous mechanisms are major challenges that are crucial for predicting their impact on the performance of subsequent multiphase processes and developing the most effective technological solutions.

The aim of the Dynamics of Evolving Fluid Interfaces DEFI event, held at IFPEN Solaize from 12 to 13 October 2016, was to address the coupling of the different mechanisms at work in multiphase industrial flows (hydrodynamics, transfer(s), physical chemistry, etc.), bringing together the various disciplines concerned in order to improve process development tools and methods. Different approaches (experimental, numerical) and different scales (micro/meso/macro) were examined. This international event also aimed to promote discussion between participants from a variety of environments (academic and industrial), addressing applications as diverse as chemical processes, water treatment, Enhanced Oil Recovery (EOR), biotechnologies, energy production, plastic processing, food production and cosmetics.
In this special issue of the OGST journal, several scientific articles highlight the need to bridge the gap between various scientific research disciplines, such as chemical engineering, fluid mechanics and physical chemistry. In recent decades, research in these areas has reached the point where boundaries have to be pushed back in order to innovate and develop technologies capable of handling multiphase flows in a large variety of industrial fields. The research studies referenced below cover a broad variety of applications, illustrating the cross-cutting nature of the themes addressed during the DEFI "Rencontre Scientifique" event. Bubbly flows were discussed in depth at the event, as was the stability of foams and micro/macro bubbles, of interest to the fields of both fluid mechanics and physical chemistry [1-3]. As reported by a variety of studies, liquid-liquid dispersion has applications in a number of fields, ranging from the accurate measurement of drop size [4] to the study of mass transfers between phases [5, 6]. Rheology issues were widely discussed throughout the conference [7], as was the development of new interfacial rheologytechniques [8]. Finally, multiphase flow modeling is obviously another major issue for the development of innovative techniques $[7,9]$.

All these topics were addressed during the event, via oral papers and keynote lectures, prompting productive discussions and promising ideas for potential collaboration between researchers. 


\section{REFERENCES}

1 Marfaing O., Guingo M., Laviéville J.M., Mimouni S. (2017) Analytical void fraction profile near the walls in low reynolds number bubbly flows in pipes: Experimental comparison and estimate of the dispersion coefficient, Oil Gas Sci. Technol. 72, 4.

2 Mezdour S., Séguineau de Préval E., Granda P., Cuvelier G., Ducept F. (2017) Impact of interfacial characteristics on foam structure: Study on model fluids and at pilot scale, Oil Gas Sci. Technol. 72, 13.

3 Ayela F., Cherief W., Colombet D., Ledoux G., Martini M., Mossaz S., Podbevsek D., Qiu X., Tillement O. (2017) Hydrodynamic cavitation through "Labs on a Chip": From fundamentals to applications, Oil Gas Sci. Technol. 72, 19.

4 Panckow R.P., Reinecke L., Cuellar M.C., Maßß S. (2017) Photo-optical in-situ measurement of drop size distributions: Applications in research and industry, Oil Gas Sci. Technol. $72,14$.

5 Lacassagne T., El-Hajem M., Morge F., Simoens S., Champagne J.Y. (2017) Study of gas liquid mass transfer in a grid stirred tank, Oil Gas Sci. Technol. 72, 7.
6 Hlawitschka M.W., Oßberger M., Backes C., Klüfers P., Bart H. J. (2017) Reactive mass transfer of single NO bubbles and bubble bouncing in aqueous ferric solutions - a feasibility study, Oil Gas Sci. Technol. 72, 11.

7 Han M., Sha Z., Laari A., Koiranen T. (2017) CFD-PBM coupled simulation of an airlift reactor with non-newtonian fluid, Oil Gas Sci. Technol. 72, 26.

8 Noirez L. (2017) Importance of interfacial interactions to access shear elasticity of liquids and understand flow induced birefringence from liquid crystals to worm-like micellar solutions, Oil Gas Sci. Technol. 72, 10.

9 Valavanides M. Oil fragmentation, interfacial surface transport and flow structure maps for two-phase flow in model pore networks. predictions based on extensive, DeProF model simulations, Oil Gas Sci. Technol. 73, 6.

Manuscript submitted in 30 November 2017 Manuscript accepted in 30 November 2017

Published online in April 2018 